\title{
WIDOWHOOD AND MENTAL ILLNESS
}

\author{
BY \\ ZENA STEIN, M.A., M.B., B.Ch. \\ Associate Professor of Epidemiology, Columbia University \\ Director, New York State Department of Mental Hygiene Epidemiology Research Unit \\ AND \\ MERVYN SUSSER, M.B., M.R.C.P.(Ed.), D.P.H. \\ Professor of Epidemiology, Columbia University
}

In this paper we examine the relationship between widowhood and mental illness as a means of approaching the general question of social and psychological causes of mental illness. A demonstrated effect of widowhood on mental illness can reasonably be taken as a special case of the social and psychological effects of bereavement.

Studies adequate to test a causal relationship between widowhood and an outcome in some sort of individual disorder are few. Apart from the many studies with unsatisfactory research designs, most studies present problems of interpretation. Thus Kraus and Lilienfeld (1959) could offer several explanations for the raised death rates of the widowed, and especially the young widowed. For instance, assortative mating leads to shared attributes between spouses, either inborn or acquired through experience before marriage, and such attributes can confer on spouses a common susceptibility to causes of disease and death. During marriage, most spouses share an intimate environment and a common exposure to many agents of disease and risks of death. After the termination of marriage, the death of one spouse may cause the death of the survivor through the social and psychological consequences of widowhood.

Problems of interpretation are compounded by problems surrounding the validity of available data. Berkson (1962) analysed manifold causes of death to show a consistent gradient running from married through single and divorced; he considered that systematic error in recorded data relating to marital state must be treated seriously as a cause of the regularity. However, Kraus and Lilienfeld (1959) showed that several such errors could not easily account for the whole of the association of widowhood with high death rates. (These errors included misrecording, the higher average age of widowers as compared with the married of the same age group, and the selection of the healthy for remarriage, thereby leaving a residuum of the unhealthy unmarried.) Credence is lent to bereavement as a factor that can cause psychological and somatic disorder by the high general death rate of widowers found in the cohort study of Young, Benjamin, and Wallis (1963), and by the high rate of suicide among the widowed found in the matched control study of MacMahon and Pugh (1965). The strength oळ these two studies resides in the demonstration of higher rates of death in a period soon after bereaves ment as compared to later periods.

To support the hypothesis that widowhood causes mental illness, uncontrolled case studies are, unfortunately, the chief material at hand. A number of analyses of mental hospital data have shown high rates of admission among the widowed (Norris, 1959; Kramer, 1965) but admission to hospital need not reflect directly the incidence of mental illness. For instance, when the widowed without the support of others in the home fall ill they are more likely to need the support of a residential institution than those who do have the support of others in the home. Moreover, such studies do not distinguish between the continuing widowed state on the one hand and the acute status transition from marriage into widowhood on the other (Susser, 1968). An association between the widowed state and mental illness is insufficient either to permit inferences about the ordering in time of the two variables, or to exclude the possible effect of many extraneous factors in bringing about the association.

Parkes (1964) was able to separate the effects of $\underset{\gamma}{ }$ continuing widowhood from the transitional event. $\mathrm{He}$, too, presented data limited to in-patients of mental hospitals, but he was able to ascertain the frequency of recent bereavement (i.e., occurring within six months before admission). Among patients admitted to the Maudsley Hospital in 
London, he found a rate of recent bereavement six times as high as an expected rate. The expected rate was obtained by applying the mortality rates for England and Wales to the age-sex distribution of the spouses of patients. This ingenious although highly indirect method must make the dubious assumption that the national death rate is applicable to the subpopulation from which Maudsley Hospital in-patients are drawn.

Bellin and Hardt (1958) eliminated the possible effect of loss of domestic support leading to higher rates of residential psychiatric care by studying a non-institutional population. They compared the responses, to a mental health rating scale, of a community sample of married and widowed people over 65 years of age living in a city of upstate New York. Although the widowed had higher scores on the rating scale, there was not a consistent relationship between scores and marital status when social class, age, and physical condition were held constant. In this prevalence study, however, continuing widowhood and the transitional event of bereavement were not separated. Neither the state of widowhood nor the state of mental health was necessarily of recent onset, and no time order could be established between the variables.

\section{The Present Study}

Widowhood and Inception of Psychiatric Care

Three sets of data drawn from a single community are presented in this paper. One set is derived from a descriptive study of the incidence of mental illness; these data strengthen the reported associations of widowhood with psychiatric care for mental illness and argue against a loss of kin support as a reason for the association. A second set of data derives from a prevalence study of chronic disability arising from mental disorder; these data indicate that there is no association between the widowed state and such chronic disability. A third set of data is derived from an analytical study aimed at testing a possible causal effect of widowhood on mental illness; these data bear on the time-interval between bereavement and first entry into psychiatric care, and support the hypothesis that the transition from the married state to widowhood precipitates entry into care for mental illness.

From 1959 to 1963 a register was maintained of all adult cases from Salford, England (population 155,090 in 1961 census) that came into any form of special psychiatric care. Every fresh referral to an agency providing psychiatric care was treated as an episode, and among them the 1,945 persons registered as seeking psychiatric care for the first time in their lives were classed as inceptions. Both the method of this incidence study and the raw data on which the analysis is based are recorded in detail elsewhere (Adelstein, Downham, Stein, and Susser, 1968; Susser, 1968). Marital state, age, sex, social class, and diagnosis were recorded for all episodes and the distributions of these attributes among patients were computed as rates against the 1961 census. A close knowledge of the community in question, derived from study and service within it for a period of eight years, inclines us to accept the relative completeness of the register of episodes with regard to severe illnesses.

At most ages the married represent the social and statistical norm in the adult population, and the widowed are selected from their ranks. Therefore we refer for a norm always to the married; as the most suitable comparison group for the widowed who are our chief concern. Rates for other marital states are tabulated for the sake of completeness but are not commented on.

Table I shows the rate of inceptions of all mental illness by sex and marital state at the time of inception, standardized for age against the total Salford population of 1961. The rates of inception were much higher for the widowed than for the married.

TABLE I

ALL MENTAL ILLNESS: INCEPTIONS BY SEX AND MARITAL STATE

\begin{tabular}{l|c|c|c|c}
\hline & \multicolumn{3}{|c}{$\begin{array}{c}\text { Average Annual Rate* per 100,000 at 1961 } \\
\text { Census, Salford, England (1959-63) }\end{array}$} \\
\cline { 2 - 5 } & Single & Married & Widowed & Divorced \\
\hline Men & 493 & 214 & 586 & 550 \\
Women & 505 & 321 & 534 & 758 \\
\hline
\end{tabular}

- Standardized against the total Salford population, for men and women separately.

Table II shows age-standardized rates of inception for selected diagnoses.

Although these community data were likely to omit few cases where they relate to diagnostic categories comprising severe mental disorders, in such categories as psychoneurosis and psychopathology they were likely to omit many mild cases and to include a disproportionate number of severe degree. The widowed had higher rates than the married for almost all diagnoses, notably for depressive psychoses among women, for addictions (most often alcoholic psychoses) among men, and for organic and senile dementias among both sexes. Only for psychoneuroses were the rates for the widowed lower than for the married among both sexes.

Table III shows inceptions for all mental illness 
TABLE II

INCEPTIONS OF SELECTED DIAGNOSES BY MARITAL STATE $\dagger$ IN EACH SEX

\begin{tabular}{|c|c|c|c|c|}
\hline & \multicolumn{4}{|c|}{$\begin{array}{l}\text { Average Annual Rate* per } 100,000 \text { at } 1961 \\
\text { Census, Salford, England (1959-63) }\end{array}$} \\
\hline & & Single & Married & Widowed \\
\hline Schizophrenia & $\begin{array}{l}\text { Men } \\
\text { Women }\end{array}$ & $\begin{array}{r}101 \\
60\end{array}$ & $\begin{array}{l}14 \\
23\end{array}$ & $\begin{array}{l}32 \\
23\end{array}$ \\
\hline Depressive & Men & 98 & 56 & 85 \\
\hline $\begin{array}{l}\text { psychosis } \\
\text { Psychoneurosis }\end{array}$ & Women & 152 & $\begin{array}{r}118 \\
49\end{array}$ & 210 \\
\hline Psychoneurosis & $\begin{array}{l}\text { Men } \\
\text { Women }\end{array}$ & $\begin{array}{l}73 \\
91\end{array}$ & $\begin{array}{l}49 \\
77\end{array}$ & $\begin{array}{l}49 \\
27\end{array}$ \\
\hline Addiction & Men & 5 & 7 & 49 \\
\hline Psychopathy & $\begin{array}{l}\text { Women } \\
\text { Men }\end{array}$ & $\begin{array}{r}5 \\
46\end{array}$ & 18 & 24 \\
\hline & Women & 41 & 11 & 27 \\
\hline Organic & $\begin{array}{l}\text { Men } \\
\text { Women }\end{array}$ & $\begin{array}{l}53 \\
17\end{array}$ & $\begin{array}{l}12 \\
15\end{array}$ & $\begin{array}{l}27 \\
39\end{array}$ \\
\hline Senile & $\begin{array}{l}\text { Men } \\
\text { Women }\end{array}$ & $\begin{array}{l}33 \\
57\end{array}$ & $\begin{array}{l}16 \\
34\end{array}$ & $\begin{array}{l}26 \\
49\end{array}$ \\
\hline
\end{tabular}

TThe divorced were considered too few in number to permit the refinement of analysis required by this table.

* Standardized against the total Salford population, for men and women separately

TABLE III

ALL MENTAL ILLNESS: INCEPTIONS BY MARITAL STATE, SEX, AND AGE GROUP

\begin{tabular}{|c|c|c|c|c|}
\hline \multirow[b]{3}{*}{ Marital State } & \multicolumn{4}{|c|}{$\begin{array}{l}\text { Average Annual Rate per } 100,000 \text { at } 1961 \text { Census } \\
\text { (numbers in parentheses), Salford, England } \\
(1959-63 \text { ) }\end{array}$} \\
\hline & \multicolumn{4}{|c|}{ Age Group } \\
\hline & $15-19$ & $20-39$ & $40-59$ & $60 \div$ \\
\hline $\begin{array}{l}\text { Men } \\
\text { Single } \\
\text { Married } \\
\text { Widowed } \\
\text { Divorced }\end{array}$ & $\begin{array}{l}197(53) \\
0(0) \\
0(0) \\
0(0)\end{array}$ & $\begin{aligned} & 418(140) \\
& 248(164) \\
& 1,364(3) \\
& 370(2)\end{aligned}$ & $\begin{array}{l}509(62) \\
202(174) \\
558(16) \\
315(4)\end{array}$ & $\begin{aligned} & 669(28) \\
& 294(97) \\
& 654(57) \\
& 1,538(3)\end{aligned}$ \\
\hline $\begin{array}{l}\text { Women } \\
\text { Single } \\
\text { Married } \\
\text { Widowed } \\
\text { Divorced }\end{array}$ & $\begin{array}{l}229(58) \\
346(8) \\
0(0) \\
0(0)\end{array}$ & $\begin{aligned} 499(101) \\
400(298) \\
1,630(11) \\
978(9)\end{aligned}$ & $\begin{array}{l}497(68) \\
255(209) \\
410(45) \\
333(6)\end{array}$ & $\begin{aligned} & 504(55) \\
& 281(78) \\
& 422(164) \\
& 1,356(4)\end{aligned}$ \\
\hline $\begin{array}{l}\text { Both sexes } \\
\text { Single } \\
\text { Married } \\
\text { Widowed } \\
\text { Divorced }\end{array}$ & $\begin{array}{c}213(111) \\
281(8) \\
0(0) \\
0(0)\end{array}$ & $\begin{array}{r}448(241) \\
328(462) \\
1,564(14) \\
753(11)\end{array}$ & $\begin{array}{ll}503 & (103) \\
228 & (383) \\
441 & (61) \\
327 & (10)\end{array}$ & $\begin{array}{l}550(83) \\
288(175) \\
464(221) \\
143(7)\end{array}$ \\
\hline
\end{tabular}

by marital state, sex, and age. In every category, save the 15-19 age group, the widowed have higher rates than the married, the differences being most marked in the 20-39 age group. This finding among the young widowed is reminiscent of the high rates for mortality among the young widowed observed by Kraus and Lilienfeld (1959), and the high rates for suicide among the young widowed observed by MacMahon and Pugh (1965).

In sum, the analysis up to this point provides strong evidence for an association of widowhood with first entry into psychiatric care. Should the relationship be a causal one, the data could be taken to point to a precipitating effect on persons predisposed to mental illness. Since the association holds in all sub-groups examined above, and for

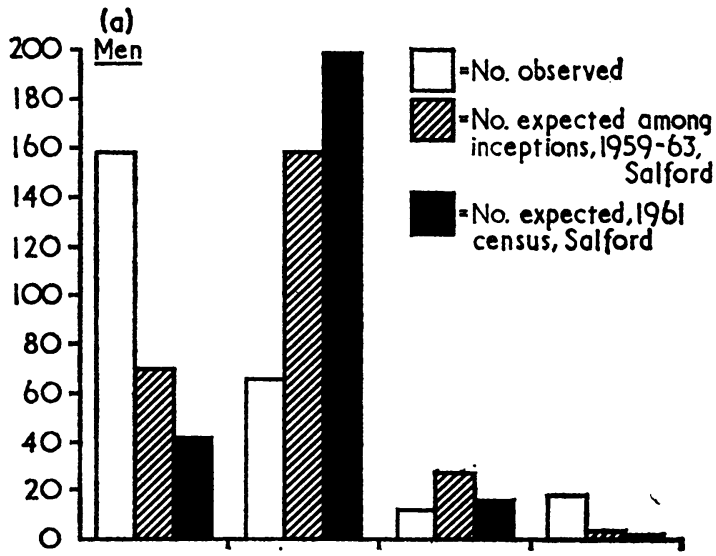

(b)

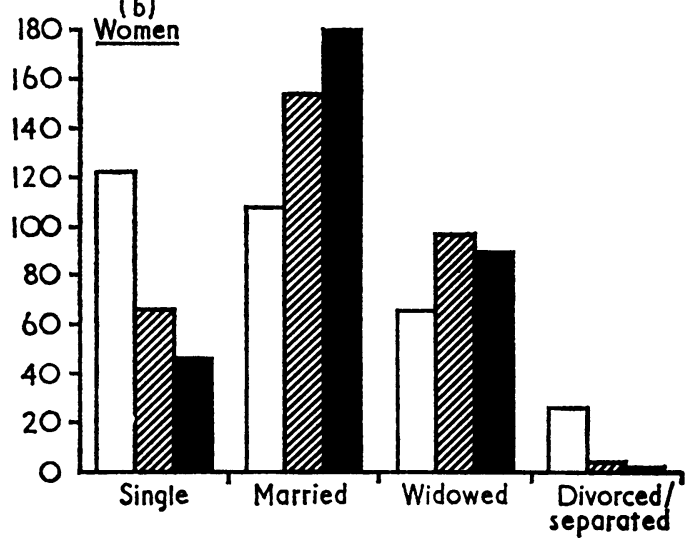

FIGURE. Numbers observed in each marital status among patients with chronic disability compared with the numbers expected, given the same age-sex distribution as the population with chronic disability (1) among inceptions (Adelstein et al., 1968), and (2) in the 1961 census.

most diagnoses, such a causal effect of widowhood could be expected to be general; it would not be expected to discriminate sharply between sub-groups, nor to apply to any special form of mental illness. Two exceptions to a general non-specific effect could be that persons widowed young would be more susceptible to the effects of bereavement than older widowed persons, and that severe psychoneurosis would be an uncommon mode of response. Among possible causes of the association between $\mathcal{N}$ widowhood and the inception of psychiatric care $N$ revealed by these data, loss of domestic support can $\underset{\mathrm{N}}{\mathrm{N}}$ probably be placed low on the list, because the study population was drawn from all types of psychiatric agency and was not confined to resident populations. Of the 1,945 inceptions, $24 \%$ were sent for in-patient $\stackrel{9}{?}$ treatment to mental hospitals and $4 \%$ to general 0 hospitals, $39 \%$ received psychiatric out-patient services at a general hospital, while the remaining 
$33 \%$ received services from the mental health services of the local authority. Thus just over one quarter of the inceptions received residential care in the first episode.

\section{Widowhood and Prevalence of Chronic Disability Associated with Mental DISORDERS}

In the same community in which the register of inceptions was compiled, a count was made, in both hospital and extramural locations, of all those with chronic disability following on mental illness. Disability was defined as either continuous failure in specified work and domestic role or as continuous residence in hospital. On 30 September 1966, from files derived from the psychiatric register, mental welfare officers of the Salford Mental Health Department made a census of all patients aged 15 years and over who had been disabled for at least one year. Some patients were resident in mental hospitals; additional returns on them were made by hospital records officers (Susser, Stein, Mountney, and Freeman, 1969).

\section{TABLE IV}

PATIENTS WITH CHRONIC DISABILITY FOLLOWING ON MENTAL ILLNESS: MARITAL STATE AND SEX

\begin{tabular}{l|rrr|rrr}
\hline & \multicolumn{3}{|c|}{ Men } & \multicolumn{3}{c}{ Women } \\
\cline { 2 - 7 } & O* & C & $I^{*}$ & O & C & I \\
\hline Single & 161 & 42 & 70 & 122 & 47 & 66 \\
Married & 68 & 199 & 159 & 108 & 180 & 153 \\
Widowed & 12 & 16 & 28 & 66 & 91 & 99 \\
Divorced/Separated & 19 & 2 & 3 & 26 & 3 & 4 \\
\hline Total & 260 & & & 322 & \\
\hline
\end{tabular}

-Distribution by marital state and sex observed $(0)$ in patients with chronic disability following on mental illness, compared with the distribution at the 1961 census (C), and at the inception of psychiatric care (I) (adjusted in each case to the age distribution of the population with chronic disability).

The expected numbers in the table have been rounded off, but in each case $\chi^{2}$ was calculated from an expected number taken to two decimal points, and then itself rounded off.
Table IV shows that among the chronically disabled the widowed were not over-represented when compared with inceptions and with the 1961 census. Indeed, fewer were widowed than in either of the two age-adjusted comparison populations. The contrast among the widowed between the high rate of inception and the low rate of chronic disability suggests that while bereavement may precipitate entry to psychiatric care, once patients have entered care, widowhood does not lead to sustained disability. A high rate of either recoveries or deaths among widows could have produced this result. An analysis of the deaths that occurred up to the end of 1965 among the inceptions of 1959 to 1963 showed that it was not due to a high rate of deaths.

\section{Transition INTO WidOWHOOD}

To examine the effect of the transition into widowhood, the same information on the duration of widowhood was collected among three populations. Two of these were overlapping sub-samples of the psychiatric register population. One subsample comprised all patients who entered psychiatric care in the calendar year 1962; they were subjects of a special survey of the complete patient population from Salford for that year. A second sub-sample comprised all patients entering care in the three-year period 1961-63, excluding those who were seen only in a psychiatric outpatient clinic of general hospitals. (An effective mechanism to collect sufficient information from these excluded out-patient clinics was not available.) Comparable data on the general population were obtained from a special survey of a random sample of households in the community conducted in 1963. This sample comprised 1,981 adults.

Table V compares each of the two sub-samples of patients with the household survey by duration of widowhood in three unequal time-intervals. As compared with the household survey sample, both sub-samples of patients show significant

TABLE V

DURATION OF WIDOWHOOD: PATIENTS COMPARED TO SURVEY POPULATION (Percentage distribution by duration of widowhood in parentheses)

\begin{tabular}{|c|c|c|c|c|c|c|c|c|c|}
\hline \multirow{2}{*}{$\begin{array}{l}\text { Duration of } \\
\text { Widowhood }\end{array}$} & \multicolumn{3}{|c|}{ All Patients 1962} & \multicolumn{3}{|c|}{$\begin{array}{l}\text { Patients 1961-63 Excluding } \\
\text { Outpatients }\end{array}$} & \multicolumn{3}{|c|}{ Household Survey } \\
\hline & Men & Women & All* & Men & Women & All $\dagger$ & Men & Women & All \\
\hline $\begin{array}{l}1-12 \text { months } \\
1-5 \text { years } \\
5 \text { or more years }\end{array}$ & $\begin{array}{l}2 \text { (18) } \\
3 \text { (27) } \\
6 \text { (55) }\end{array}$ & $\begin{array}{l}4(12) \\
13(38) \\
17(50)\end{array}$ & $\begin{array}{r}6(13) \\
16(36) \\
23(51)\end{array}$ & $\begin{array}{r}5(21) \\
8(33) \\
11(46)\end{array}$ & $\begin{array}{l}11(12) \\
20(23) \\
57(65)\end{array}$ & $\begin{array}{l}16(14) \\
28(25) \\
68(61)\end{array}$ & $\begin{array}{c}2(6) \\
10(28) \\
24(67)\end{array}$ & $\begin{array}{r}7(4) \\
28(15) \\
148(81)\end{array}$ & $\begin{array}{r}9(4) \\
38(17) \\
172(79)\end{array}$ \\
\hline Total No. & $11(100)$ & $34(100)$ & $45(100)$ & $24(100)$ & $88(100)$ & $112(100)$ & $36(101)$ & $183(100)$ & $219(100)$ \\
\hline
\end{tabular}

- Comparing distribution of duration of widowhood among All Patients 1962 (All) and Household Survey (All), $\chi^{2}=15.43$, df $=2$. The null hypothesis that duration of widowhood is not associated with inceptions of mental illness is rejected $\mathbf{P}<0.005$.

+Comparing distribution of duration of widowhood among Patients 1961-1963 (All) and Household Survey (All), $\chi^{2}=15 \cdot 58$, df $=2$. The null hypothesis that duration of widowhood is not associated with inceptions of mental illness is rejected, $P<0.005$. 
clustering in the earliest time-interval after loss of the spouse, that is, in the first year. The patient populations were older than the subjects of the household survey, but this could not account for the clustering, for in each of the three samples the older age groups had a smaller proportion than the younger of persons recently widowed. By inference, this time-relation between the transition into widowhood and entry into psychiatric care provides strong support for a causal effect of the transition on entry to care. In turn, on the assumption that the community psychiatric register includes most severe cases of mental illness, first entry to care is presumptive evidence of the inception of severe mental illness.

\section{CONCLUSION}

We conclude from this analysis first that widowhood is associated with the inception of psychiatric care, an outcome which we believe reflects in fair degree the inception of severe mental illness. Second, widowhood is not associated with chronic disablement arising from mental illness. Third, among the widowed the inception of care for mental illness, and presumably the inception of mental illness itself, follow closely on the event of bereavement more often than expected by chance. These results support the causal hypotheses that transition into widowhood is a precipitating factor in the seeking of psychiatric care, and probably in the inception of mental illness. Since recent widowhood reflects a change in social status and role, the specific results may illustrate consequences that are general to such changes, and may repay further exploration in this context.

\section{SUMMARY}

This paper supports the hypothesis that recent widowhood precipitates the seeking of psychiatric care and, presumptively, the inception of mental illness.

Three sets of data relating to the same population were presented. One set of data, derived from a register of all adult cases from Salford, England, that came into any form of psychiatric care for the first time in their lives, strengthened the inferences to be drawn from previously reported associations of widowhood with mental hospital admissions. In particular, the need of widowed persons for residential care, following loss of kin support, cannot explain away the association of widowhood and the seeking of psychiatric care in this study population.

A second set of data, derived from a prevalence study of chronic disability arising from mental disorder, showed no association between widow- $\infty$ hood and chronic disability, and suggested that widowhood did not play a part in sustaining the $\frac{\pi}{\mathbb{D}}$ state of chronic disability.

A third set of data related to the time interval $\underset{\vec{\rho}}{\vec{\rho}}$ between bereavement and first entry into psychiatric care. As compared with a random community household sample, these data showed clustering of $\frac{\overline{\bar{p}}}{\overline{\frac{p}{p}}}$ inception of care in the earliest period after bereave- $\vec{\nabla}$ ment. This result points to the transition into $\frac{0}{0}$ widowhood as a cause of entry to psychiatric care, $\infty$ and probably of the onset of mental illness.

We thank the Mental Welfare Officers of Salford for collecting the relevant data, and Mrs. H. Millward for tabulat ing them. Dr. J. L. Burn, Medical Officer of Health, facilitated this study in every way. The Medical $\mathrm{\omega}_{\omega}$ Research Council of Great Britain and the Salford iv Mayoral Fund (Mellor) gave financial assistance.

We thank Dr. Joseph Fleiss, New York State Bio- 으 metrics Research Unit, for careful comments on the manuscript. Mr. Frank Marolla, New York StateEpidemiology Research Unit, Division of Epidemiology, 3 and Miss Marilyn Schoenfeld assisted at various stages of the analysis, and we thank them.

\section{REFERENCES}

Adelste in, A. M., DownhaM, D. Y., Stein, Z., ante SUSSER, M. W. (1968). The epidemiology of mental illness in an English city: Inceptions recognized by Salford Psychiatric Services. Social Psychiat., 3, 47.

Bellin, S. S., and HARdT, R. H. (1958). Marital status and mental disorders among the aged. Amer. Soc. $\overrightarrow{\overrightarrow{0}}$ Rev., 23, 155.

BERKSON, J. (1962). Mortality and marital status. Amer. J. publ. Hlth, 52, 1318.

KrAMER, M. (1965). Some implications of trend in the usage of psychiatric facilities for community health $\frac{1}{5}$ programs and related research, read at the Annual Meeting of the American College of Neuropharmacology, December 13-15, San Juan, Puerto Rico.

Kraus, A. S., and Lilienfeld, A. M. (1959). Some epidemiologic aspects of the high mortality rate in the young widowed group. J. chron. Dis., 10, 207.

MacMahon, M., and PUGH, T. F. (1965). Suicide in the $>$ widowed. Amer. J. Epidem., 81, 23.

NoRRIS, V. (1959). Mental Illness in London. [Maudsley Monographs, Number 6.] Chapman and Hall, London. क

PARKeS, M. C. (1964). Recent bereavement as a cause of N mental illness. Brit. J. Psychiat., 110, 198.

SUSSER, M. W. (1968). Community Psychiatry: Epidemiologic and Social Themes. Random House, New York.

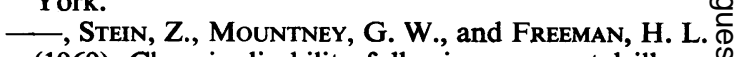
(1969). Chronic disability following on mental illness? in an English city. Soc. Psychiat. (in the press).

Young, M., Benjamin, B., and Wallis, C. (1963). The mortality of widowers. Lancet, 2,454 . 